03;09;10

\title{
Особенности спектроскопии при лазерном пробое воды и водных растворов в ультразвуковом поле
}

\author{
(C) А.В. Буланов ${ }^{1,3,4}$, И.Г. Нагорный ${ }^{2,3}$, Е.В. Соседко ${ }^{1}$ \\ ${ }^{1}$ Тихоокеанский океанологический институт им. В.И. Ильичева ДВО РАН, \\ Владивосток \\ ${ }^{2}$ Институт автоматики и процессов управления ДВО РАН, Владивосток \\ ${ }^{3}$ Дальневосточный федеральный университет, Владивосток \\ ${ }^{4}$ Морской государственный университет им. адм. Г.И. Невельского, \\ Владивосток \\ E-mail: a_bulanov@me.com
}

Поступило в Редакцию 28 декабря 2016 г.

Показано, что при воздействии ультразвука наблюдаются резкое увеличение акустической эмиссии и увеличение интенсивности спектральных линий растворенных элементов в водных растворах $\mathrm{NaCl}, \mathrm{NaHCO}_{3}$ и $\mathrm{CaCl}_{2}$, что позволяет говорить о новом комбинированном методе лазерной и ультразвуковой искровой спектроскопии. Решена задача синхронизации акустического и оптического излучения, что позволило выявить зависимость интенсивности спектральных линий от фазы ультразвукового воздействия.

DOI: $10.21883 /$ PJTF.2017.16.44933.16650

Лазерно-искровая спектроскопия (ЛИС) твердых объектов является широко используемой технологией, применяется и в промышленности, и в научных исследованиях [1-3]. Актуальность изучения механизмов генерации оптического пробоя в жидкости связана с разработкой новых оптико-акустических источников звука и методов оптико-акустической диагностики сред [1], а также с применением метода ЛИС для элементного анализа жидкостей [2-4]. Вместе с тем механизм оптического пробоя при облучении мощным лазерным излучением водных мишеней существенным образом отличается от механизма взаимодействия лазерного излучения с металлами и другими твердыми телами. Со спектроскопическим анализом жидкостей сопряжены трудности, связанные с тем, что, как правило, применяется пробой на поверхности жидкостей, 


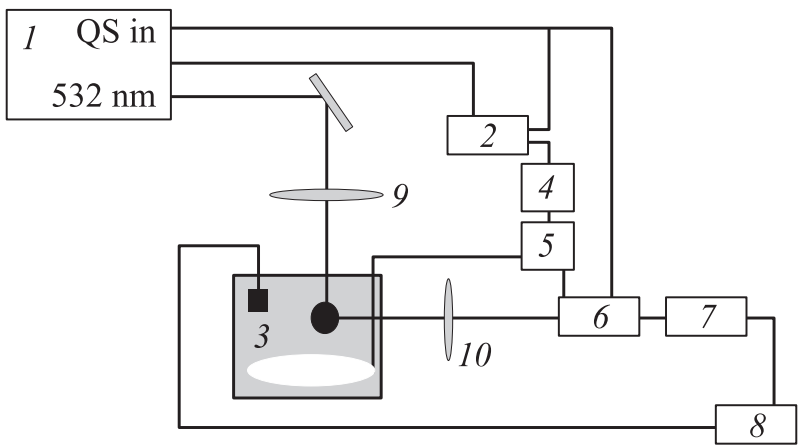

Рис. 1. Схема эксперимента.

где в свою очередь мощный вклад вносят линии атмосферных газов. Выход заключается в использовании пробоя в толще жидкости, так как в этом случае посторонний эффект газа исключается [4,5]. Однако в этом случае имеется дополнительная трудность, связанная с ослаблением возбуждаемых слабых линий элементов вследствие поглощения в жидкости. Поэтому важным является повышение интенсивности линий при пробое. Казалось бы очевидно, что повышение мощности лазерного облучения могло бы стать способом преодоления этой трудности. Однако ряд экспериментов [4-6] свидетельствует об обратном парадоксальном эффекте: начиная с определенных порогов повышение мощности облучения не приводит к усилению интенсивности высвечиваемых линий элементов. Представляло интерес изучить воздействие дополнительного акустического излучения на процесс лазерного пробоя с целью выявить возможность его влияния на повышение интенсивности линий элементов, возбуждаемых при таком комбинированном пробое жидкости. Полученные результаты представлены далее.

С использованием наносекундного лазера в широкой временной области была изучена динамика лазерного пробоя с традиционной оптической регистрацией пробоя в наносекундной области и на более поздних стадиях. Для этого был проведен ряд экспериментов для возбуждения оптического пробоя в толще жидкости с использованием $\mathrm{Nd}$ :YAG-лазера „BrilliantB“, работающего в режиме модулированной добротности, со следующими параметрами излучения: длина вол-

Письма в ЖТФ, 2017, том 43, вып. 16 
ны $532 \mathrm{~nm}$, длительность импульса $10 \mathrm{~ns}$, энергия в импульсе до $500 \mathrm{~mJ}$. Схема эксперимента представлена на рис. 1. Плотность мощности лазерного излучения дополнительно возрастала за счет острой фокусировки излучения в необходимом месте (в толще жидкости или вблизи поверхности жидкости) с помощью линз (2) с различными фокусными расстояниями $(F=40,75$ и $125 \mathrm{~mm})$. При этом в зависимости от применения короткофокусной или длиннофокусной линзы менялся характер распределения в области пробоя. Регистрация оптического пробоя осуществлялась с применением оптического многоканального анализатора спектров FlameVisionPROSystem с временнб́м разрешением 3 ns.

Эксперименты проводились по следующей схеме. Излучение лазеpa (I) с помощью поворотного зеркала и линзы (9) фокусировалось в жидкость. Излучение плазмы оптического пробоя проецировалось линзой (10) на входную щель монохроматора (7), сопряженного с CCD-камерой (6). Управление осуществлялось компьютером (8). Для анализа динамики пробоя и параметров акустической волны, инициируемой оптическим пробоем, в качестве широкополосного акустического приемника использовался гидрофон типа 8103 фирмы Brüel\&Kjær (3), информация с которого оцифровывалась и записывалась с применением многоканальной платы ввода-вывода E20-10 фирмы L-Card (максимальная частота оцифровки $\sim 5 \mathrm{MHz}$ ). Для излучения ультразвуком использовались цифровой генератор импульсов произвольной формы ГСПФ 053 (4) и усилитель мощности У7-5 (5)[6-8].

В работе была решена задача синхронизации акустического и оптического излучения. Изменяя длительность задержки управляющих импульсов, можно было синхронизировать момент максимального растяжения или сжатия жидкости акустическими импульсами и начало оптического пробоя. Решение данной задачи позволило эффективно использовать небольшие по мощности (на пороге кавитации) источники ультразвука, которые предопределяли уменьшение порога пробоя в толще жидкости. Была создана методика, позволяющая использовать звуковое облучение области пробоя с применением пьезокерамических акустических излучателей с различными резонансными частотами. Для синхронизации акустических и оптических импульсов использовался генератор задержек. Синхронизация и измерение акустической эмиссии проводились измерительным гидрофоном с одновременной регистрацией пробоя в оптической области спектра.

Письма в ЖТФ, 2017, том 43, вып. 16 

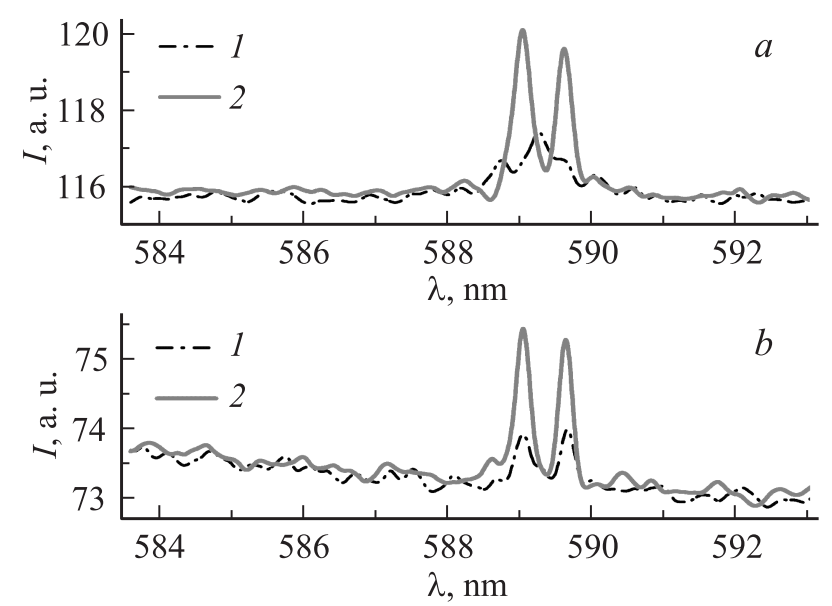

Рис. 2. Интенсивность линий $I$ натрия без использования $(1)$ и с использованием (2) ультразвука при концентрации раствора $\mathrm{NaCl}$, равной $10(a)$ и $3.5 \%(b)$.

Исследования спектроскопических параметров лазерного пробоя были проведены при различных концентрациях соли при наличии и в отсутствие поля ультразвука. Это дало возможность увеличить интенсивность отдельных спектральных линий (а некоторые линии удалось разрешить при воздействии ультразвука), что позволяет говорить о новом комбинированном методе лазерной и ультразвуковой искровой спектроскопии.

В первую очередь было выявлено влияние концентрации растворенных веществ в растворе на оптоакустические эффекты. Показано, что существует разный характер пробоя при различной концентрации растворенной соли в воде. Экспериментальным подтверждением данного явления стало обнаружение усиления интенсивности линий натрия при различных концентрациях соли $\mathrm{NaCl}$ и $\mathrm{NaHCO}_{3}$.

На рис. 2 представлены линии натрия при лазерном пробое с дополнительным использованием ультразвука и без ультразвука при разных концентрациях $\mathrm{NaCl}$ (для $10 \%$ и $3.5 \%$ раствора $\mathrm{NaCl}$; последнее ее значение, в частности, соответствует типичной концентрации соли в воде Японского моря). Следует отметить, что лазерное излучение было пороговым для пробоя жидкости и эффект усиления линии проявлялся наиболее ярко. 


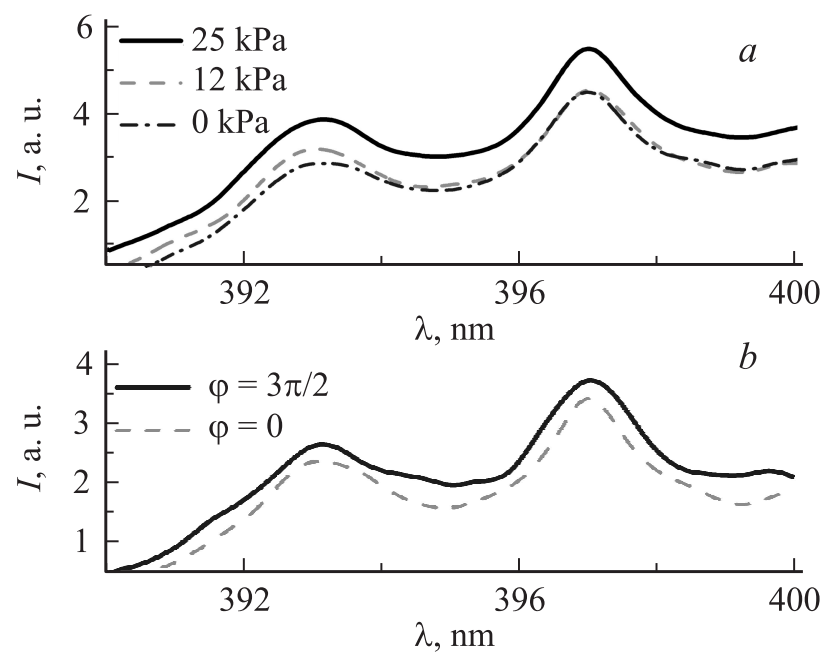

Рис. 3. $a-$ усиление интенсивности $I$ линии иона кальция в зависимости от амплитуды акустического излучения при давлении $0,12,25 \mathrm{kPa} . b-$ усиление интенсивности $I$ линий однократного ионизированного дублета кальция (Са II) в зависимости от фазы акустического поля $(3 \pi / 2-$ фаза растяжения, $0-$ фаза, в которой влияние ультразвука несущественно).

Как видно из рис. 2, усиление линии под воздействием ультразвука наблюдается при всех концентрациях используемых растворов, что свидетельствует об эффективности спектроскопического возбуждения жидкости ультразвуком. Причина эффекта неясна. Возможно, эффект усиления связан с пробоем на стенке кавитируемого пузырька от ультразвука, что является пробоем на границе раздела двух сред. Понижение порога пробоя также предположительно может быть вызвано механизмом совместного электроакустического взаимодействия в сильном электролите. Последнее может приводить к дополнительной диссипации энергии в фокальной области взаимодействия лазерного излучения с раствором, вследствие которого возникают дополнительный перегрев и облегчение образования полостей в жидкости.

При использовании модуляции и синхронизации акустического и оптического излучения по методике, описанной выше, было определено возрастание интенсивности линии другого элемента - кальция - при

Письма в ЖТФ, 2017, том 43, вып. 16 
различных мощностях лазерного излучения. На рис. 3, $a$ представлена зависимость интенсивности линии кальция от амплитуды акустического излучения (при давлении $0,12,25 \mathrm{kPa}$ ) при пороговом постоянном лазерном излучении. Видно, что с увеличением мощности акустического излучения возрастает интенсивность линии при пороговом лазерном излучении. На рис. 3, $b$ представлено усиление линии иона кальция на длинах волн 393.4 и $396.8 \mathrm{~nm}$ в фазе растяжения и нулевой фазе, когда влияние ультразвуковой волны несущественно. Видно, что в фазе растяжения происходит усиление интенсивности линии иона кальция по сравнению со случаем отсутствия ультразвука.

Таким образом, показано, что при воздействии ультразвука наблюдается усиление линии при всех концентрациях используемых растворов, что свидетельствует об эффективности спектроскопического возбуждения жидкости ультразвуком. Представленная методика синхронизации акустического и оптического излучения позволила определить зависимость интенсивности спектральных линий от фазы ультразвукового воздействия. Полученные результаты свидетельствуют о возможности повышения эффективности ЛИС жидкости в поле ультразвука и позволяют говорить о возможности прикладного применения ультразвука в технологии ЛИС.

Работа выполнена при поддержке РФФИ (проекты № 16-02-00841-а, 15-32-20878 мол_а_вед).

\section{Список литературы}

[1] Davies C.M., Telle H.H., Montgomery D.J. // Spectrochem. Acta B. 1995. V. 50. P. 1059-1075.

[2] Cremers D.A., Radziemski L.J. Handbook of laser-induced breakdown spectroscopy. N.Y.: John Wiley \& Sons. 2006. P. 282.

[3] Sturm V., Peter L., Noll R. // Appl. Spectrosc. 2000. V. 54. P. 1275-1278.

[4] Michel A.P.M., Lawrence-Snyder M., Angel S.M., Chave A.D. // Appl. Spectrosc. 2007. V. 61. N 2. P. 171-176.

[5] Bulanov A.V., Nagorny I.G. // Proc. SPIE. 2016. V. 10176. P. 10176F.

[6] Bulanov A.V., Nagorny I.G. // AIP Conf. Proc. 2015. V. 1685. P. 030005 (1-4).

[7] Bulanov A.V. // Proc. Mtgs. Acoust. V. 24. P. 070014 (1-7).

[8] Буланов А.В., Нагорный И.Г., Соседко Е.В. // ЖТФ. 2013. Т. 83. В. 8. С. $117-$ 120. 